\title{
25 years of satellite InSAR monitoring of ground instability and coastal geohazards in the archaeological site of Capo Colonna, Italy
}

\author{
F. Cigna ${ }^{* a}$, P. Confuorto ${ }^{\mathrm{b}}$, A. Novellino ${ }^{\mathrm{c}}$, D. Tapete ${ }^{\mathrm{a}}$, D. Di Martire ${ }^{\mathrm{b}}$, M. Ramondini ${ }^{\mathrm{b}}$, \\ D. Calcaterra ${ }^{b}$, S. Plank ${ }^{\mathrm{d}}$, F. Ietto ${ }^{\mathrm{e}}$, A. Brigante ${ }^{\mathrm{f}}$, A. Sowter ${ }^{\mathrm{c}}$ \\ ${ }^{a}$ British Geological Survey, United Kingdom; ${ }^{b}$ Federico II University of Napoli, Italy; \\ ${ }^{\mathrm{c}}$ Geomatic Ventures Ltd, Nottingham, UK; ${ }^{\mathrm{d}}$ German Aerospace Center, Germany; \\ ${ }^{\mathrm{e}}$ Università della Calabria, Rende, Italy; ${ }^{\mathrm{f}}$ Brigante Engineering Srl, Italy
}

\begin{abstract}
For centuries the promontory of Capo Colonna in Calabria region, southern Italy, experienced land subsidence and coastline retreat to an extent that the archaeological ruins of the ancient Greek sanctuary are currently under threat of cliff failure, toppling and irreversible loss. Gas extraction in nearby wells is a further anthropogenic element to account for at the regional scale. Exploiting an unprecedented satellite Synthetic Aperture Radar (SAR) time series including ERS-1/2, ENVISAT, TerraSAR-X, COSMO-SkyMed and Sentinel-1A data stacks acquired between 1992 and 2016, this paper presents the first and most complete Interferometric SAR (InSAR) baseline assessment of land subsidence and coastal processes affecting Capo Colonna. We analyse the regional displacement trends, the correlation between vertical displacements with gas extraction volumes, the impact on stability of the archaeological heritage, and the coastal geohazard susceptibility. In the last 25 years, the land has subsided uninterruptedly, with highest annual line-of-sight deformation rates ranging between -15 and $-20 \mathrm{~mm} /$ year in 2011-2014. The installation of 40 pairs of corner reflectors along the northern coastline and within the archaeological park resulted in an improved imaging capability and higher density of measurement points. This proved to be beneficial for the ground stability assessment of recent archaeological excavations, in an area where field surveying in November 2015 highlighted new events of cliff failure. The conceptual model developed suggests that combining InSAR results, geomorphological assessments and inventorying of wavestorms will contribute to unveil the complexity of coastal geohazards in Capo Colonna.
\end{abstract}

Keywords: InSAR, PSInSAR, SBAS, CPT, ground motion, coastal erosion, land subsidence, cultural heritage

\section{INTRODUCTION}

There is a copious literature investigating the natural and human-induced land subsidence along the eastern coast of Calabria region in southern Italy, as well as its correlation with geological and tectonic setting, temporal evolution and impact on the landscape [1-4]. Earliest evidence of ground instability and subsidence was found in the archaeological records of the Ancient Greek sites distributed along the Ionian coast [5-7]. Among these, Capo Colonna is of particular interest for its cultural value, as it was known for centuries for the glorious sanctuary of the Greek Goddess Hera Lacinia (Figure 1). Although only one monumental column is preserved [8-9], the site is nowadays the archaeological icon of the region and, for this reason, a focus for the heritage bodies that are responsible for its preservation.

Capo Colonna has been imaged by space-borne Synthetic Aperture Radar (SAR) sensors over the last 25 years, resulting in an unprecedented SAR time series encompassing ERS-1/2 (1992-2000), ENVISAT ASAR (2003-2010), TerraSAR-X StripMap (2008-2010), COSMO-SkyMed StripMap (2011-2015) and Sentinel-1A Interferometric Wide Swath (20142016) scenes. This is therefore an interesting case study representing the increasing number of sites for which the combination of past and current satellite SAR missions at present provides an almost uninterrupted digital record of space-derived ground stability information.

With the primary purpose of developing the first and most complete baseline assessment of land subsidence and coastal processes affecting the archaeological site of Capo Colonna, in this work annual rates and temporal evolution of ground motions were analysed as they are estimated through Interferometric SAR (InSAR) processing with the Permanent Scatterer InSAR (PSInSAR), Coherent Pixel Technique - Temporal Sublook Coherence (CPT-TSC), Persistent Scatterer Pairs Differential InSAR (PSP-DIFSAR), Small Baseline Subset (SBAS) and Intermittent SBAS (ISBAS) techniques.

*fcigna@bgs.ac.uk; phone +44 1159363551

SAR Image Analysis, Modeling, and Techniques XVI, edited by Claudia Notarnicola, Simonetta Paloscia, Nazzareno Pierdicca, Edward Mitchard, Proc. of SPIE Vol. 10003, 100030Q - () 2016 SPIE CCC code: $0277-786 X / 16 / \$ 18 \cdot$ doi: $10.1117 / 12.2242095$ 


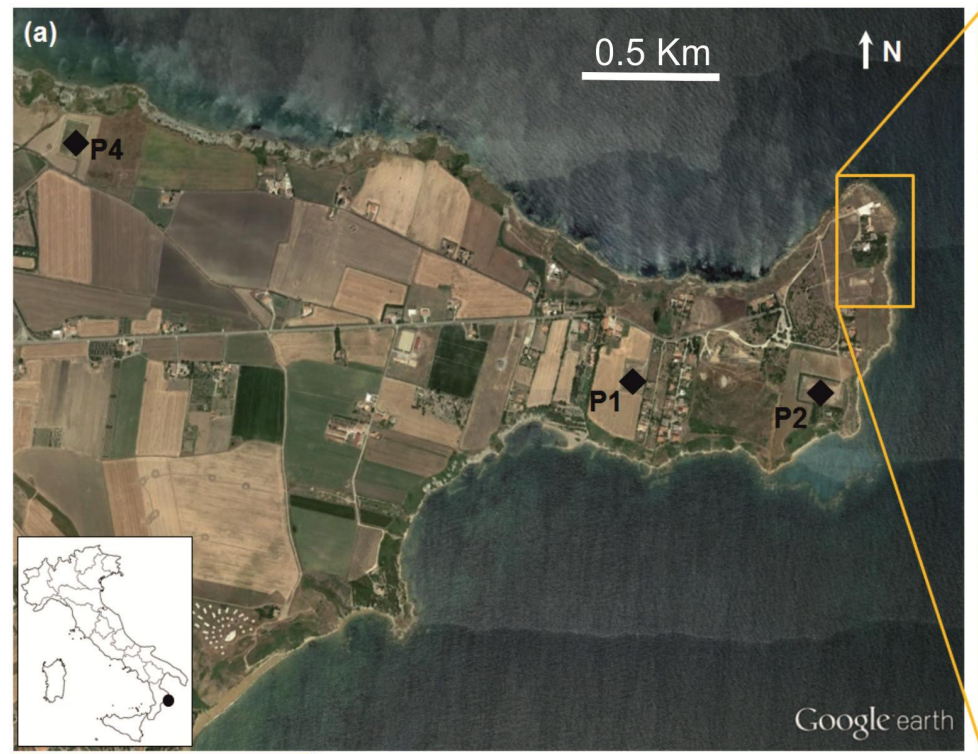

(c)

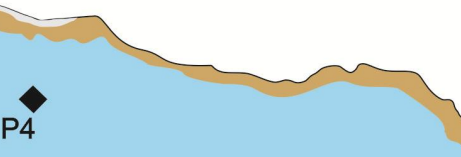

\section{Ionian Sea}

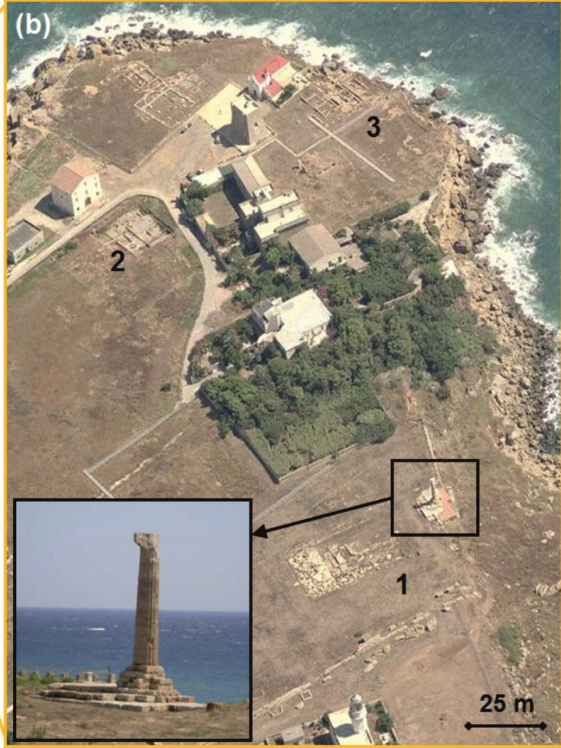

$\uparrow \mathrm{N}$

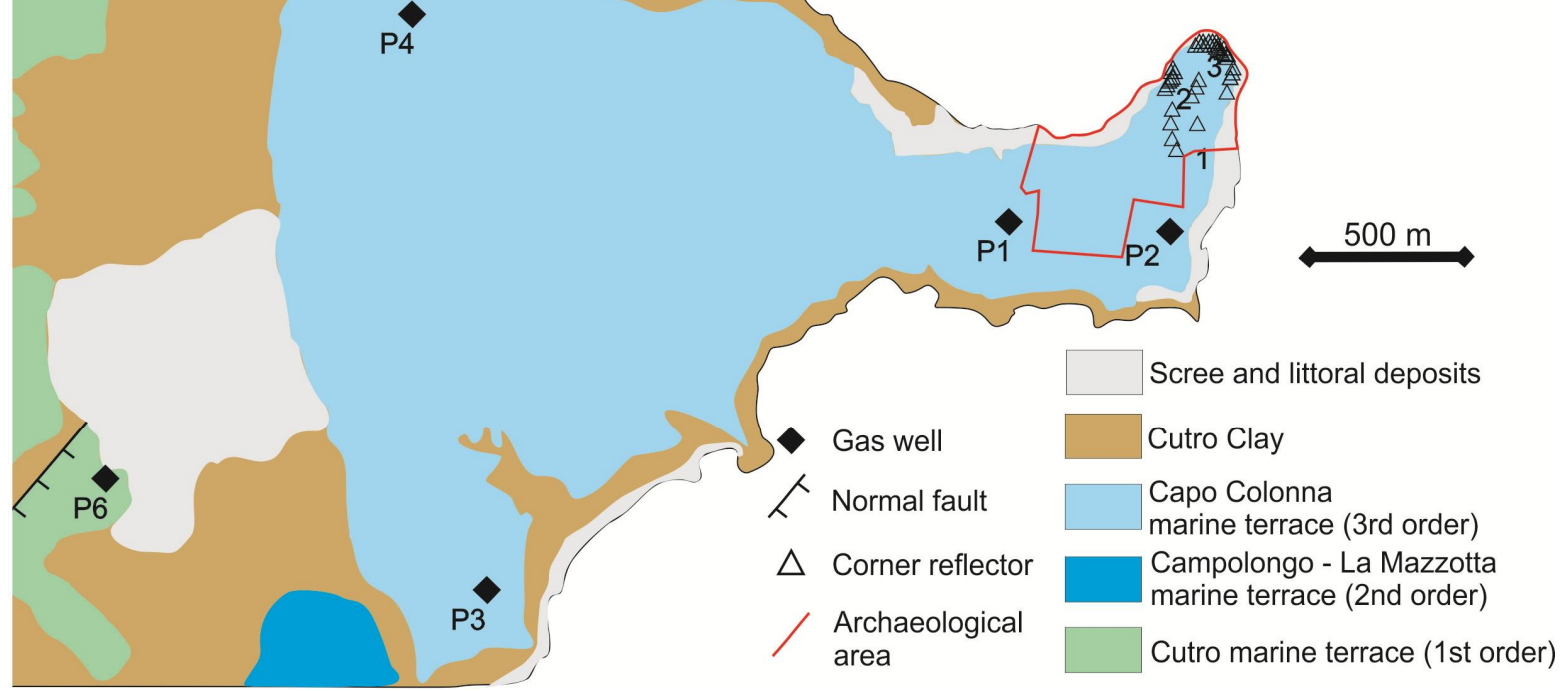

Figure 1. (a) Google Earth image (23/06/2015) of Capo Colonna and the Lacinio promontory in Calabria region, southern Italy (Google Earth (C) 2016 Digital Globe). (b) Zoomed view of (1) the Column and Temple A; (2) balneum and building M; and (3) Capo Nao Tower and St. Mary Sanctuary, within the archaeological park of Capo Colonna (modified from [16]). (c) Geological map of the Capo Colonna promontory (modified from [14]) with indication of the extent of the archaeological area and location of radar corner reflectors. Three marine terrace deposits (Middle-Late Pleistocene), unconformably overlying the Plio-Pleistocene deep marine Cutro Clay, are present in the area.

The goal of our multi-sensor, multi-temporal and multi-processing approach is to test different spatial resolutions, radar wavelengths and InSAR processing routines and provide an improved understanding of the performances of these data and methods over an archaeological area that is known to have been uninterruptedly exposed to land subsidence and coastal processes of instability, but challenging to monitor with InSAR methods due to its chiefly rural setting.

This study is timely in that it follows from recent developments in the research on Capo Colonna, including the installation of 40 pairs of corner reflectors within the Lacinio promontory in October 2014 carried out by Brigante Engineering and Langella S.r.l., in the framework of a project funded by the Commission for the Architectural and 
Landscape Heritage of the Calabria Region (Soprintendenza per i Beni Archeologici della Calabria). The installation of these artificial reflectors was designed to improve the visibility of some sectors of the site in the SAR images during the acquisition campaign with COSMO-SkyMed StripMap products from October 2014 to September 2015. The role of these reflectors was particularly crucial along the cliffs, to improve the density of monitoring targets along the coastline and throughout the area of the archaeological ruins which are affected by significant erosion, as reported by several authors in the last two decades [10-12].

\subsection{Study area}

The archaeological site of Capo Colonna occupies the head of an EW-elongated promontory extending $3 \mathrm{~km}$. With an eastward dip of about $1^{\circ}$, the promontory overlooks the Ionian Sea, south-east of Crotone, and derives its name from the columns of the Greek temple dedicated to the goddess Hera (Figure 1). The monument was the landmark for ancient sailors for centuries, but nowadays only one column still stands, as most of the monument was demolished to source building materials [8-9]. The Column was carved from the local calcarenite and is founded on a thick sandstone base, at the margin of a composite terrace, very close to the rock cliffs (Figure 1b), at about $15 \mathrm{~m}$ a.s.l. The terrace terminates against a steep slope seawards, while the landward border of the promontory is placed at about $50 \mathrm{~m}$ of elevation. The upper part of the promontory is occupied by the staircase of three marine terraces (Middle to Late Pleistocene), of which the Capo Colonna terrace is the youngest (Figure 1c). The latter consists of carbonate and siliciclastic sediments (up to $10 \mathrm{~m}$ thick) unconformably overlying the Plio-Pleistocene slope succession of the Cutro Clay Formation [13-14]. The Ntrending internal border of the terrace represents a paleo-coastline.

The constant action of sea erosion undermines the cliff and generates rockfalls and collapses [7], with a total retreat of $150 \mathrm{~m}$ observed in the last 110 years at the north-eastern tip [15]. Here, the ruins of the ancient Roman settlement are perilously distributed along the cliff edge, directly facing the sea, with high susceptibility to masonry collapses and toppling as a consequence of rockfalls [16]. Further geohazard for the preservation of the archaeological remains is represented by the subsidence that historically affects the entire promontory. Scientists recognized the origin of such phenomenon in a combination of millennial natural processes (e.g., lithostratigraphic setting, seismic activity and eustatic sea-level changes) and, since the late 1970s, hydrocarbon extraction [17-18]. Figure 1a,c report the location of the gas wells in the proximity of the study area which are managed by the national hydrocarbons authority ENI (Ente Nazionale Idrocarburi).

In a holistic perspective, the above mentioned processes might contribute to a wide-area evolution of the substratum instability across the promontory. The combination of land subsidence from inland and accelerated retreat of the coast from the sea might exacerbate the impacts on the conservation of the archaeological site in the near future, with local destabilization, if not even the loss, of the standing structures.

\subsection{Monitoring data}

Table 1 lists the 9 SAR data stacks and the associated InSAR time series that were used for this study and either accessed at already processed Persistent Scatterers (PS) level, or processed ad hoc by the authors.

The earliest data are the C-band ERS-1/2 and ENVISAT PS data from the Extraordinary Plan of Environmental Remote Sensing (EPRS-E) funded by the Italian Ministry of the Environment, Territory and Sea (MATTM) [19]. For the EPRSE, ERS-1/2 processing was undertaken using the PSInSAR ${ }^{\text {TM }}$ technique [20], with a simple linear model of phase variation through time and false alarm rate of $10^{-5}$. ENVISAT PS data were processed with the PSP-DIFSAR approach (Persistent Scatterers Pairs - DIFferential InSAR [21]). In both cases only PS with a coherence $\gamma \geq 0.6$ were considered. Both the datasets are characterised by a nominal monthly temporal frequency of 35 days and, overall, account for nearly two-thirds of the 25-year long monitoring period (Figure 2).

Higher resolution SAR time series from the TerraSAR-X and COSMO-SkyMed X-band satellite constellations allowed us to extend the temporal coverage from April 2008 to September 2015, with only two data gaps from June 2010 to May 2011 and from April 2014 to October 2014. Some solutions to fill these gaps could be found, e.g. a time series of C-band RADARSAT-2 Fine 4 beam mode with monthly sampling for the 2010-2011 gap. Although access to additional data with respect to those listed in Table 1 is outside the scope of this research, it is worth noting that a potentially more conspicuous SAR archive record is available over Capo Colonna. 
Table 1. SAR data stacks and associated InSAR time series that are analysed in this study. Asc (ascending) and Desc (descending) geometry; PSInSAR ${ }^{\mathrm{TM}}$ [20]; PSP-DIFSAR [21-22]; SBAS [23]; CPT-TSC [24]; ISBAS [25-26]

\begin{tabular}{|c|c|c|c|c|c|}
\hline Satellite & Orbit & Dates & \# scenes & Technique & Literature \\
\hline ERS-1/2 & Desc & $18 / 06 / 1992-17 / 12 / 2000$ & 52 & PSInSAR $^{\mathrm{TM}}$ & \\
\hline ERS-1/2 & Asc & $27 / 03 / 1995-17 / 10 / 2000$ & 24 & PSInSAR $^{\mathrm{TM}}$ & {$[16]$} \\
\hline ENVISAT & Asc & $24 / 06 / 2003-27 / 07 / 2010$ & 44 & PSP-DIFSAR & \\
\hline TerraSAR-X & Desc & $25 / 04 / 2008-26 / 06 / 2010$ & 67 & SBAS & {$[28-29]$} \\
\hline TerraSAR-X & Asc & $27 / 04 / 2008-28 / 06 / 2010$ & 66 & SBAS & \\
\hline COSMO-SkyMed & Asc & $25 / 10 / 2011-03 / 01 / 2014$ & 44 & PSP-DIFSAR & n/a \\
\hline COSMO-SkyMed & Desc & $19 / 05 / 2011-25 / 04 / 2014$ & 46 & PSP-DIFSAR \\
\hline COSMO-SkyMed & Desc & $17 / 10 / 2014-18 / 09 / 2015$ & 26 & CPT-TSC & \\
\hline Sentinel-1A & Asc & $03 / 10 / 2014-25 / 05 / 2016$ & 46 & ISBAS & \\
\hline
\end{tabular}

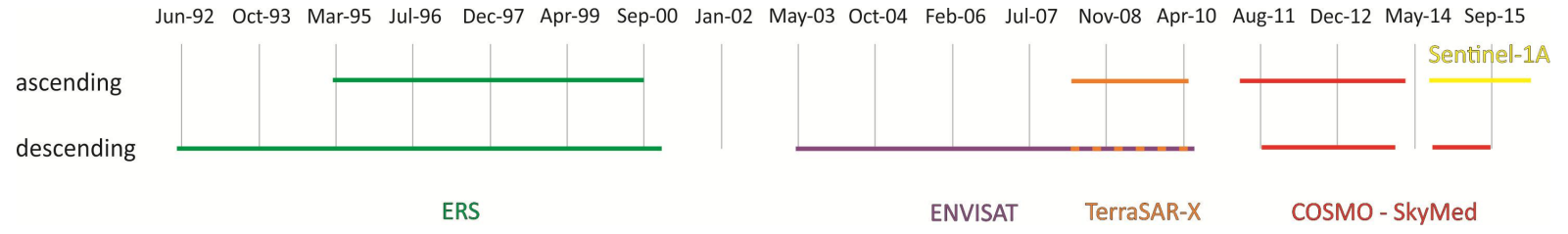

Figure 2. Temporal coverage of the 9 SAR data stacks processed and analysed over Capo Colonna.

TerraSAR-X StripMap ascending and descending products acquired in 2008-2010 were processed for this study using the Small BAseline Subset technique (SBAS) [23], implemented on the SARscapeC software, using multi-looking of $5 \times$ 5 (azimuth $\times$ range), $\gamma \geq 0.6$ and perpendicular and temporal baseline thresholds of $120 \mathrm{~m}$ and 100 days, respectively.

COSMO-SkyMed StripMap HIMAGE PS for the 2011-2014 period belong to the second phase of EPRS-E, which led to the integration of the ERS-1/2 and ENVISAT database with more recent information at higher resolution through COSMO-SkyMed data processed with the PSP-DIFSAR [22] algorithm using $\gamma \geq 0.7$.

To complement this dataset and exploit the opportunity offered by the installation of 40 pairs of corner reflectors along the northern cliff of the Lacinio promontory (see section 1; Figure 1), 26 COSMO-SkyMed StripMap HIMAGE products were also acquired from October 2014 to September 2015 and processed with the Coherent Pixel Technique - Temporal Sublook Coherence (CPT-TSC) approach [24] and using spatial and temporal baseline thresholds of $300 \mathrm{~m}$ and 300 days, respectively. The latter are part of a research project funded by the Commission for the Architectural and Landscape Heritage of the Calabria Region, with the main goal to improve the quality of data monitoring of the area by increasing the temporal coherence of the COSMO-SkyMed StripMap products over the coastline by means of the artificial reflectors. The deployment strategy for the 40 pairs of reflectors was made according to the parameters of the COSMOSkyMed acquisition geometry to maximise the radar backscattering in both the ascending and descending mode.

Finally, Sentinel-1A ascending mode images acquired between October 2014 and May 2016 (Table 1) and made available via the Sentinel Scientific Data Hub [27] were processed using an improved version of the ISBAS technique [25-26]. To create the small baseline interferograms a threshold of one-year temporal baseline was used, while values of the perpendicular baseline were all below $200 \mathrm{~m}$, hence complying with the common threshold used in SBAS processing. Multi-looking using a $5 \times 22$ (azimuth $\times$ range) window size was applied, thereby producing pixels of $\sim 90 \mathrm{~m}$ in ground range. Coherent points display an average $\gamma \geq 0.3$, in at least 120 interferograms.

Our approach was therefore to combine already processed data with new PS and SBAS products to retrieve as much extended and constant temporal and spatial coverage as possible over Capo Colonna and the inland, being conscious of the advantages and limitations of the different data stacks and processing algorithms. On one hand, wide-area processing with techniques such as ISBAS was preferred to obtain a regional-scale baseline map of land subsidence with a better depiction of ground motions occurring across the predominantly rural land cover of the study area. Whilst on the other 
hand, higher resolution SAR data processed with PS and CPT-TSC techniques allowed improved assessment of the impacts on the key archaeological assets owing to the higher density of identified targets, particularly over the ruins which are also exposed to structural instability triggered by coastal erosion.

\section{MULTI-TEMPORAL ANALYSIS OF GROUND INSTABILITY}

\subsection{Regional-scale assessment}

Figure 3 provides an overview of the PS, SBAS, CPT-TSC and ISBAS products collected, processed and analysed in this study and the associated annual velocities estimated along the Line Of Sight (LOS) of the respective satellites and orbit modes, either ascending or descending.

Over a total land area of $\sim 9.3 \mathrm{~km}^{2}$, the point density ranges from a minimum of $8 \mathrm{PS} / \mathrm{km}^{2}$ (i.e. ERS-1/2 ascending stack in Figure 3a) to a maximum of $750 \mathrm{PS} / \mathrm{km}^{2}$ (COSMO-SkyMed descending stack in Figure $3 \mathrm{~g}$ ). Overall, there is good agreement between motion rates estimated between 1992 and 2016, with a distinctive subsidence pattern mostly concentrated within the Capo Colonna marine terrace (compare with Figure 1c). The highest displacement rates are found in the sector between gas wells P1 and P4, with average LOS velocity of up to $-18 \mathrm{~mm} /$ year.

The PSInSAR ${ }^{\mathrm{TM}}$ ERS ascending (Figure 3a) and descending (Figure 3b) data confirm the occurrence of land subsidence, especially since May 1995, over the whole promontory, with a large area characterised by a homogeneous deformation pattern of $-6 \mathrm{~mm} /$ year within the archaeological site, for a total of 6 PS in the ascending geometry and 10 PS in the descending one. Going westward inland, LOS velocities tend to increase, reaching values up to $-10 \mathrm{~mm} / \mathrm{year}$. The main subsidence pattern is concentrated within the calcareous units of the Capo Colonna marine terrace which constitutes the foundation of the archaeological structures [16].

Clear evidence of subsidence with the same trend is found after 2000, as depicted by the PSP-DIFSAR ENVISAT ascending data (Figure 3c), with LOS annual velocities greater in the central part of the promontory ( -5 to $-13 \mathrm{~mm} /$ year) than the coastal area. It is to be noted that, while the PS coverage is as good as in ERS-1/2 descending data (Figure $3 b$ ), PSP-DIFSAR processing of ENVISAT ascending images provide a much better coverage not only across the archaeological site as a whole (with a total of 35 PS), but also along the northern coast of the promontory where 6 ENVISAT PS are found, against the only 2 PS of the ERS ascending and 3 PS of the ERS descending results.

Unfortunately, the same cannot be stated in the case of the SBAS processing of TerraSAR-X ascending (Figure 3d) and descending (Figure 3e). Few pixels are found in the archaeological site ( $\sim 50$ and $\sim 200$ in the ascending and descending datasets, respectively). On the other side, adequate pixel coverage was obtained over the inland area where subsidence progressed since April 2008, with clusters of moving targets with annual LOS velocities up to $-15 \mathrm{~mm} /$ year in the rural and cultivated fields located west of the archaeological site. Given the land use, it cannot be excluded that local groundwater pumping contributes to the overall subsidence, adding onto the geological component of this process [2829]. In both the TerraSAR-X geometries, the area of gas well P1 is markedly one of the subsidence hot spots, while the lack of pixels near P4 in the ascending geometry (Figure 3d) constraints the assessment.

During the period 2011-2014 covered by PSP-DIFSAR COSMO-SkyMed results (Figure 3f-g), the highest annual LOS deformation rates take on values ranging between -15 and $-20 \mathrm{~mm} / \mathrm{year}$, with hot spots of subsidence close to gas wells P1 and P4. These are the highest values observed over the 25-year long period of InSAR monitoring. In both geometries, high PS densities are achieved in the archaeological site and the whole coastline of the promontory. COSMO-SkyMed targets show significant displacements along the Capo Colonna cliffs, with LOS velocity up to $-4.3 \mathrm{~mm} / \mathrm{year}$, both in the southern and northern sectors of the promontory. In this latter sector, field survey (see also section 3 ) confirmed that the combined action of land subsidence and wave erosion extensively affect the marine terrace generating meter-scale fractures filled with siliciclastic sandstone of scree and littoral deposits. The negative LOS displacement rates observed therefore capture the associated motions and tilts of the bedrock outcrop and cliff edges.

Less clear confined patterns of subsidence are found in the Sentinel-1A ISBAS results (Figure 3h) which highlight a slight decrease in the annual LOS velocities of subsidence around the gas extraction sites, with values never exceeding -8 $\mathrm{mm} /$ year. Nonetheless, the sparse distribution of pixels moving away from the satellite LOS confirms the presence of a general trend of subsidence. Within the archaeological area, subsidence estimates do not exceed $-5 \mathrm{~mm} /$ year, a value that aligns with the evidence obtained in all the previous ascending InSAR datasets. 

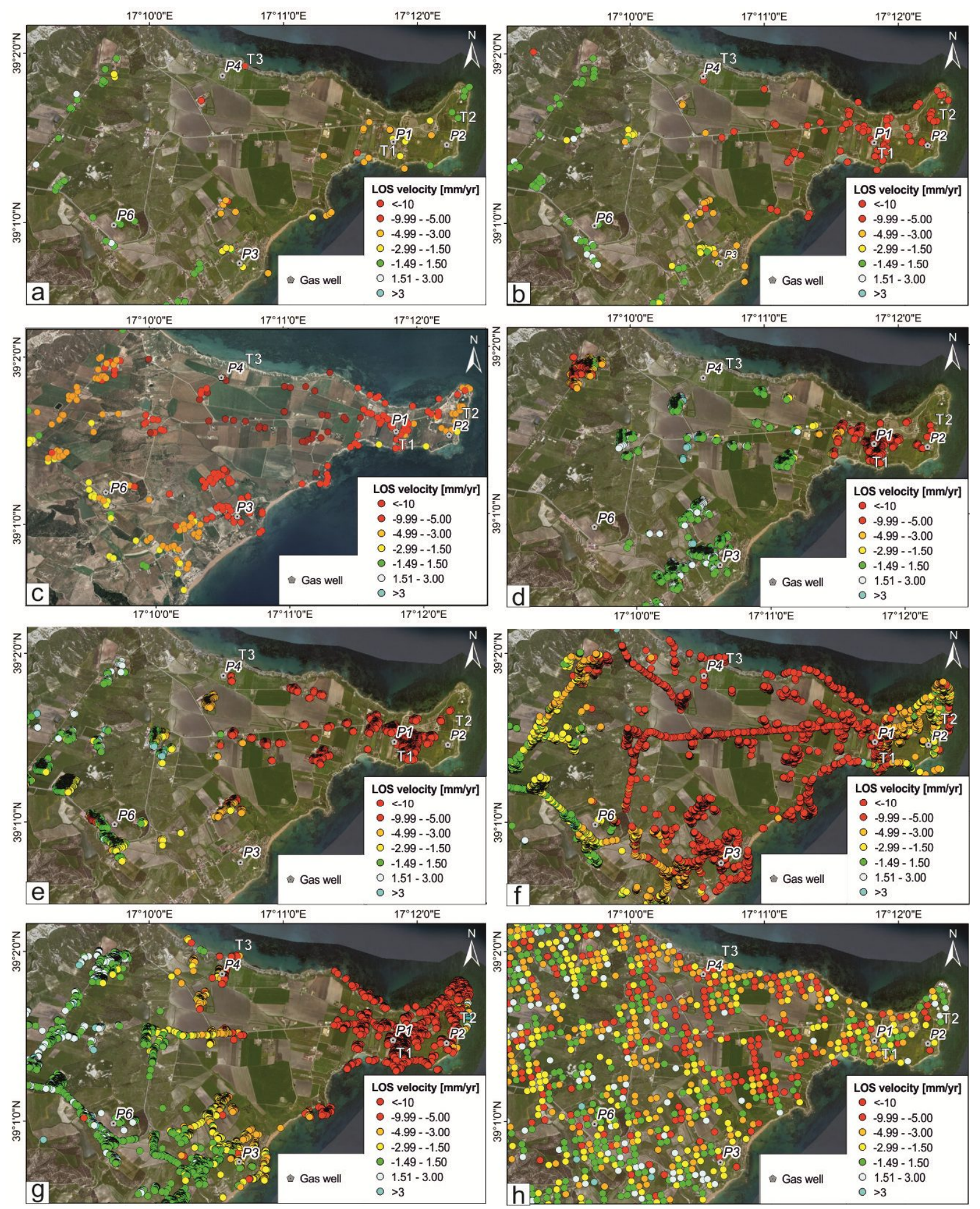

Figure 3. Annual LOS velocity in Capo Colonna and the inland region estimated by using: ERS-1/2 (a) ascending and (b) descending data (1992-2000); (c) ENVISAT ascending data (2003-2010); TerraSAR-X (d) ascending and (e) descending data (2008-2010); COSMO-SkyMed (f) ascending and (g) descending data (2011-2014); and (h) Sentinel-1A ascending data (2014-2016). InSAR data are overlapped onto ArcGIS Online basemap. T1, T2 and T3 time series are shown in Figure 6. 


\subsection{Lacinio promontory and archaeological park}

Figure 4 shows the results of the local-scale CPT-TSC processing of the COSMO-SkyMed StripMap images covering the interval October 2014 - September 2015 over the Lacinio promontory. The installation of the metallic and rectangular trihedral corner reflectors resulted in $\sim 15 \mathrm{~dB}$ higher amplitude values, thereby improving the imaging capability along the toe of the promontory, within the archaeological site [28-29] and, consequently, increasing the number of measurement points retrieved. The best performance was achieved along the narrow strip of the cliff edge running parallel to the road leading to the wide place in front of Nao Tower. This is well evidenced by the comparison with the spatial coverage of both the COSMO-SkyMed ascending and descending time series processed with PSPDIFSAR prior to the installation of the corner reflectors (Figure 5).

In addition to the main subsidence trend, three localised micro-sectors of instability can be identified in the archaeological area (Figure 4a), in agreement with the previous satellite investigation using the ENVISAT PS data [16]: (1) Hera Lacinia Temple; (2) balneum and building M; and (3) Capo Nao Tower and St. Mary Sanctuary. Within sector 1 , the Column and the surrounding basement show displacements with average LOS deformation rate of $-8 \mathrm{~mm} /$ year, almost doubling the $-4.8 \mathrm{~mm} /$ year estimated with ENVISAT. The analysis of the time series reveal different periods of acceleration (see Figure 6b). Localised displacements affect both the ruins and the ground at the SW corner of the balneum and building area (sector 2), with average LOS velocity of $-5.6 \mathrm{~mm} /$ year in the period 2003-2010 increasing to $9.7 \mathrm{~mm} /$ year during 2014-2015. Similar changes in the displacement trend are observed in the time series of the measurement points identified on the architectural structures of Capo Nao Tower and the church (sector 3).

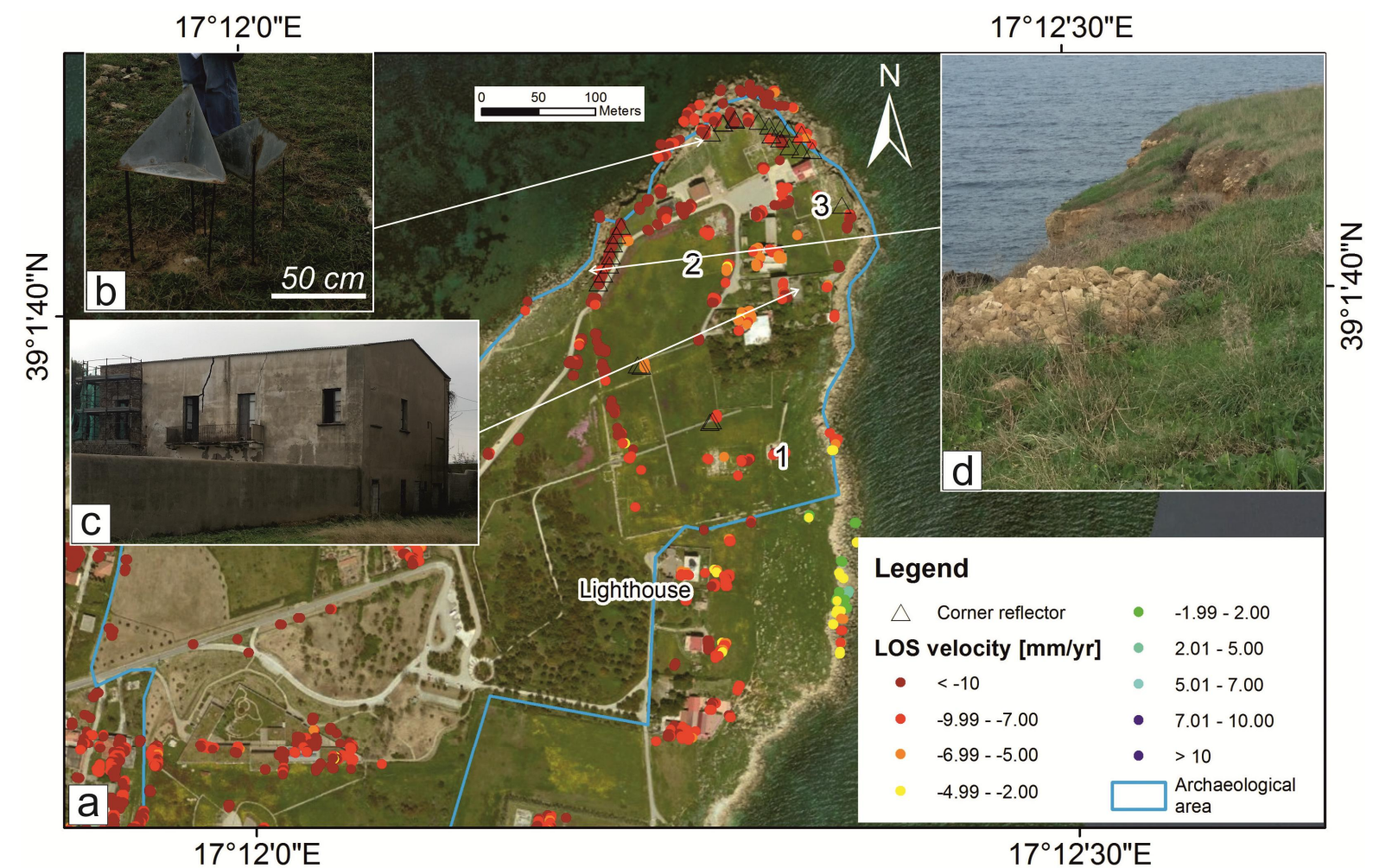

Figure 4. (a) Spatial distribution and associated average LOS velocity of COSMO-SkyMed CPT-TSC data (2014-2015) over the archaeological park of Capo Colonna, with indication of: (1) the Column and Temple A; (2) balneum and building M; and (3) Capo Nao Tower and St. Mary Sanctuary (see also Figure 1b,c). InSAR data are overlapped onto ArcGIS Online basemap (b) A pair of corner reflectors installed in the northern end of the Lacinio promontory; (c) structural damage observed in one of the residential buildings; (d) niche $\rightarrow$ crown of coastal cliff failure triggered by sea erosion (photo credit: P. Confuorto, 07/11/2015). Project carried out using COSMO-SkyMed® PRODUCTS, C ASI (Italian Space Agency) provided under license of ASI. 


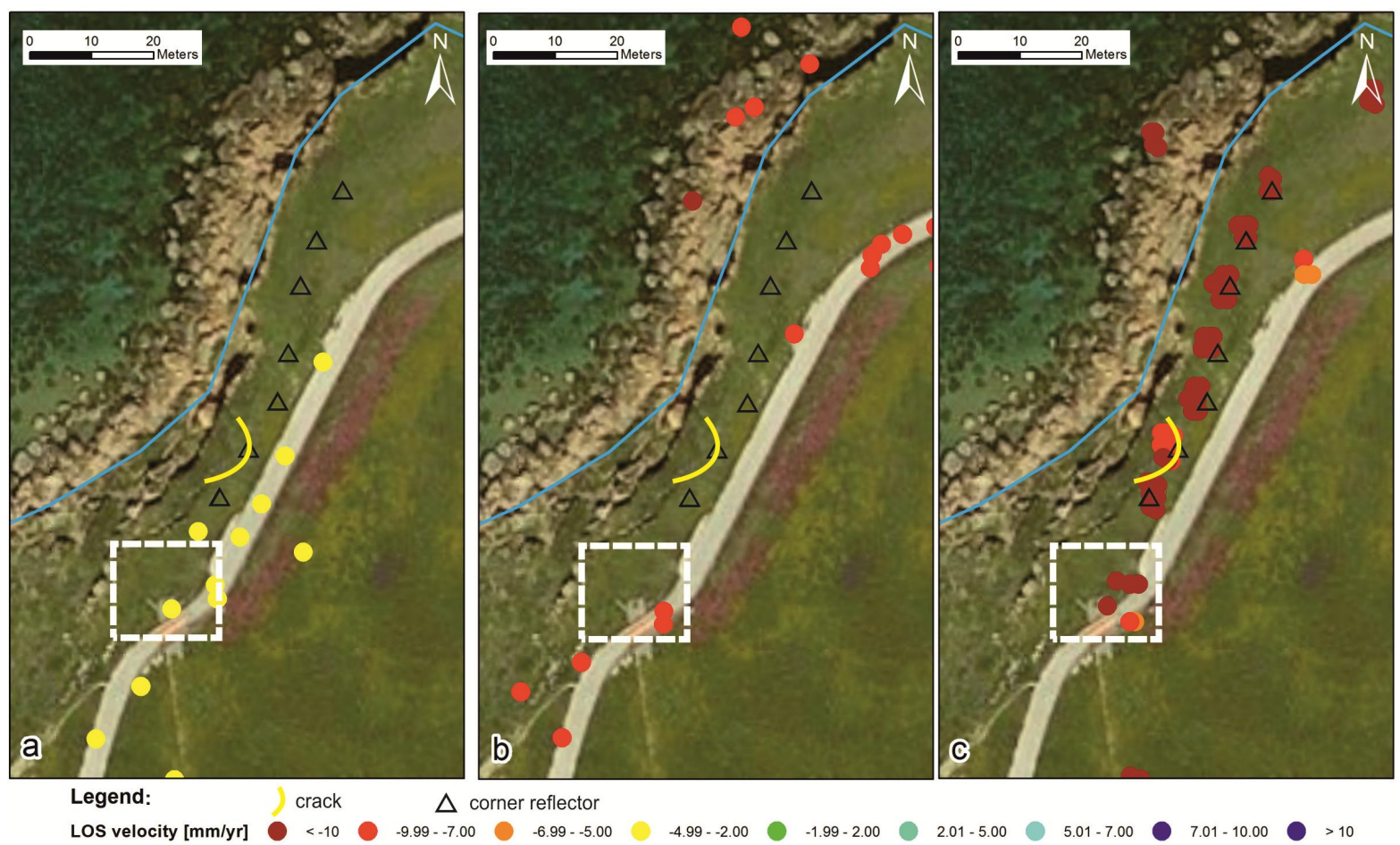

Figure 5. Spatial distribution and annual LOS velocity of COSMO-SkyMed (a-b) PSP-DIFSAR data (2011-2014) in (a) ascending and (b) descending mode, and (c) CPT-TSC descending mode data (2014-2015) in the cliff edge sector where the ruins of one of the Roman city wall towers were discovered in 2013 (see dashed rectangle). A photo of the crack is reported in Figure 4d. InSAR data are overlapped onto ArcGIS Online basemap. Subsidence and cliff instability are apparent in the 3 datasets (see also Figure 4d), alongside the improved target density where the corner reflectors were installed.

Other radar targets characterised by displacement rates higher than $-10 \mathrm{~mm} /$ year can be observed near the museum, some of the nearby private houses (Figure 4c) and the lighthouse, south of Temple A. Several measurement points located at the toe of the northern cliffs suggest tilt and displacements of the boulders already detached, or in the process of detaching, from the rock cliffs. On the other hand, the positive LOS velocities found in the SE sector of the promontory are likely due to the accumulation of debris as a cascading effect of the erosional activity of the sea waves, consequent cliff retreat and simultaneous shoreline accretion. It is to be noted that this portion of the coast degrades more gently towards the sea, as opposed to the steep cliffs in the northern end of the promontory.

\subsection{Vertical velocity and time series analysis}

Due to the inherent property of the side-looking geometry of SAR systems, conventional InSAR can estimate only the one-dimensional (1D) land displacements along the radar LOS [30]. Nevertheless, the availability of both ascending and descending ERS-1/2 (1992-2000), TerraSAR-X (2008-2010) and COSMO-SkyMed (2011-2014) datasets, allows us to combine the two geometries and decompose the displacement vector into its vertical and horizontal components, according to equations:

$$
\begin{aligned}
& d_{e}=\frac{\mathrm{D}_{a} \times \cos \theta_{d}-\mathrm{D}_{d} \times \cos \theta_{a}}{\sin \left(\theta_{a}+\theta_{d}\right)} \\
& d_{z}=\frac{\mathrm{D}_{d} \times \sin \theta_{a}+\mathrm{D}_{a} \times \sin \theta_{d}}{\sin \left(\theta_{a}+\theta_{d}\right)}
\end{aligned}
$$

and

where $\theta_{a}$ and $\theta_{d}$ are the look angles for both orbit modes $d$ the displacement of point $\mathrm{P}, D_{d}$ and $D_{a}$ the displacements measured along the descending and ascending LOS respectively, $d_{z}$ and $d_{e}$ the retrieved vertical and horizontal components of the displacement $d$. 
On the other hand, in the case of ENVISAT (2003-2010), COSMO-SkyMed (2014-2015) and Sentinel-1A (2014-2016) results for which only one acquisition geometry is available, the vertical displacements can be estimated under the assumption of negligible horizontal motion $\left(d_{e}=0\right)$, and simply by dividing the LOS displacements $D_{d}$ and $D_{a}$ by the cosine of the look angle $\theta_{d}$ or $\theta_{a}$, respectively:

$$
\begin{aligned}
& d_{z}=\frac{\mathrm{D}_{d}}{\cos \left(\theta_{d}\right)} \\
& d_{z}=\frac{\mathrm{D}_{a}}{\cos \left(\theta_{a}\right)}
\end{aligned}
$$

Or

Figure 6 shows the time series of vertical displacements obtained by stitching the individual time series available from ERS-1/2 to Sentinel-1A for three target areas considered the most representative of the different processes occurring in Capo Colonna since 1992: (a) land subsidence in the surrounding of gas extraction well P1; (b) structural instability of the Column of the Greek temple A; and (c) combination of land subsidence and ground instability due to marine erosion of the cliffs along the northern coastline.

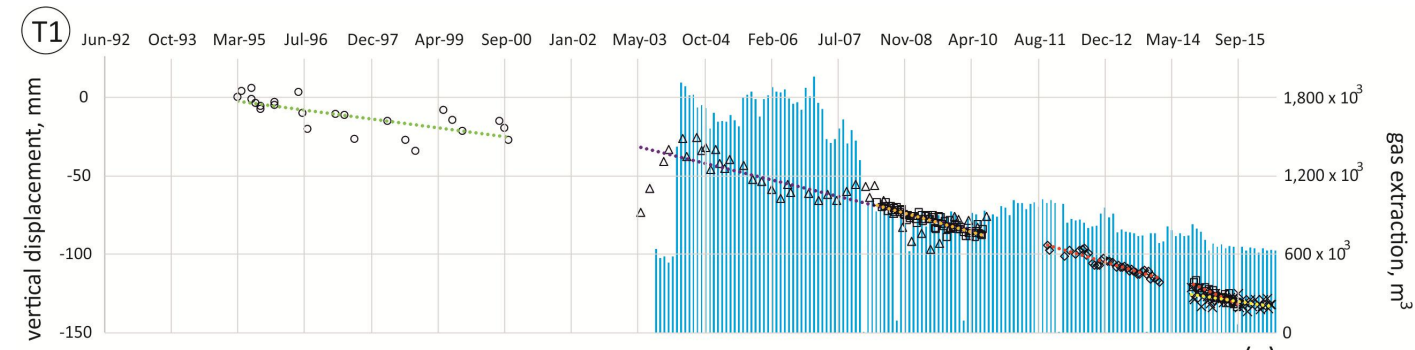

(a)

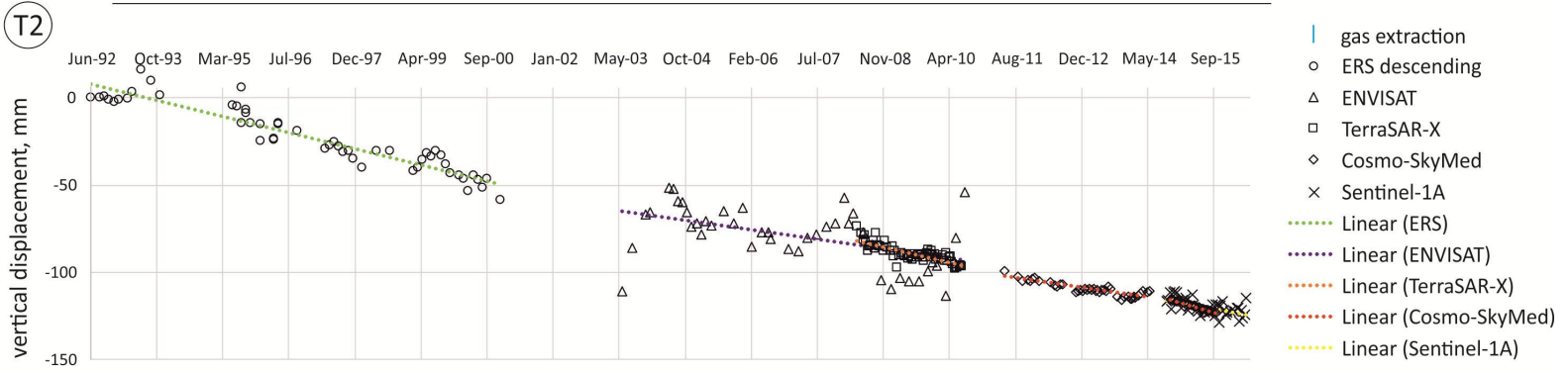

(b)

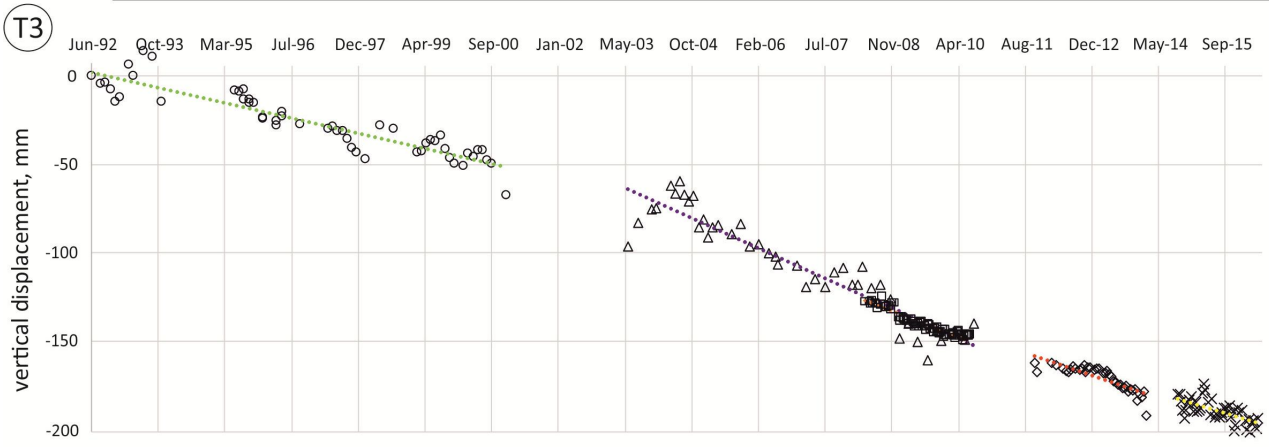

(c)

Figure 6. Time series of vertical displacement obtained by stitching the individual time series from ERS-1/2 to Sentinel-1A for three key areas: (a) production well P1; (b) the Column of Temple A; and (c) northern coastal area. Their location is shown in Figure 3. Data of gas extraction from well P1 showed in (a) were accessed from the Italian Ministry of Economic Development (MISE) [31]. 
The three time series show a similar plurennial subsidence trend, with an increase of the vertical displacement rates, especially observed during the ENVISAT period. This suggests that, despite some differences due to the different nature of the objects on the ground and local actors of instability, there is a general trend common to the whole promontory.

The comparison between the time series of well P1 and the volume of extracted gas recorded since 2003 highlights an apparent correlation. From January to July 2004, the monthly gas extraction volume was lower than $600,000 \mathrm{~m}^{3}$ and the vertical displacements were positive. Pending further investigations, a plausible explanation to the observed positive rate might be ground heave, as if the land surrounding well P1 was reacting to this lowered extraction rate and recovering pre-extraction conditions. In correspondence to the gas extraction boost since July-August 2004, there is an inversion of the vertical motion trend from uplift to subsidence. On the other hand, despite the halving from over $18,000,000 \mathrm{~m}^{3} /$ year in January 2004 - February 2008 to $\sim 9,000,000 \mathrm{~m}^{3} /$ year afterwards, the observed motion rate is unchanged.

\section{DISCUSSION AND CONCLUSIONS}

The analysis presented in this paper is the first ever baseline assessment of the land surface processes affecting Capo Colonna as observed in the last 25 years from space radar platforms. It is apparent that in this long period, the land has subsided uninterruptedly, although some accelerations and decelerations have been observed. The agreement between the different SAR data stacks and different processing techniques is appreciated in the similarity of the spatial patterns and time series trends.

Capo Colonna is therefore a demonstrative example of the capabilities of multi-sensor InSAR approaches to track the evolution of surface processes in continuity, whenever a wealth of legacy SAR data and new imaging solutions is available. This situation is increasingly becoming more frequent, as longer time series are stored in the space agency catalogues and archive data are made accessible, not only for major urban centres and supersites of global scientific and civil protection interest, but also for rural and more peripheral sites such as Capo Colonna. The presence of assets of economic, social, cultural or amenity values can stimulate baseline studies and local-scale investigation of this type.

One of the constraints to the achievement of robust results that may be claimed, though, is the heterogeneity of the SAR data. Differences in wavelength, acquisition geometries, spatial and temporal resolutions are certainly elements to account for, especially when planning new acquisitions, as opposed to the archive data for which these parameters cannot be modified or improved retrospectively. In this regard, the schedule of COSMO-SkyMed StripMap acquisitions for the period 2014-2015 with parameters matching those of already available COSMO-SkyMed time series from the EPRS-E goes in the direction of reducing the number of variables to ensure comparability between different data stacks. Similar considerations can be made with regard to the processing algorithms, although in the specific case of this research the availability of InSAR products generated with different processing chains was purposely exploited to assess the performance at the different scales of investigation.

Some considerations can therefore be drawn. Higher spatial and temporal resolutions of the SAR data not necessarily translate into a higher density of the measurement points, as demonstrated in the case of the TerraSAR-X results. The use of either SBAS or PS approaches played a role, alongside the local properties of land cover, absence or presence of radar targets and visibility to the satellite LOS, to result in a poor coverage along the coastline of the promontory and the archaeological park and higher pixel density in the inland.

At equal conditions of the rural landscape, the choice of using a technique such as ISBAS aiming to extend the number of pixels across non-urban land covers seems to have paid off in this respect. For Capo Colonna, this was indeed particularly helpful to process a data stack like the Sentinel-1A that was not sufficiently long to highlight clear and distinctive long-term patterns of ground motions such as those seen over longer time scales via the ERS-1/2 and ENVISAT C-band analyses with similar acquisition parameters. Despite the relatively short monitoring interval and coarse spatial resolution of the Sentinel-1 IW data stack, this first ISBAS trial provided a deformation scenario consistent with the historical trend, paving the way for future exploitation of longer time series.

The experiment with the artificial corner reflectors installed within the archaeological site proves the benefits of this solution that has a minimal impact on the amenity of the archaeological landscape, although it requires efforts and investment for long-term maintenance. The results also suggest a satisfactory performance of the CPT-TSC approach which overcomes the limitation of the full-resolution PS routines requiring larger number of SAR images. 
The coastal area is indeed the part of the promontory where InSAR can help us to improve our understanding of the potential threats for Capo Colonna. The LOS and vertical displacements are surface indicators of two simultaneous processes: land subsidence progressively lowering the ground elevation of the archaeological park and the sea erosion that undermines the cliffs inducing block detachment and exposing new surfaces to erosion. Figure 7 shows the conceptual model developed, also accounting for the InSAR observations analysed in this study.

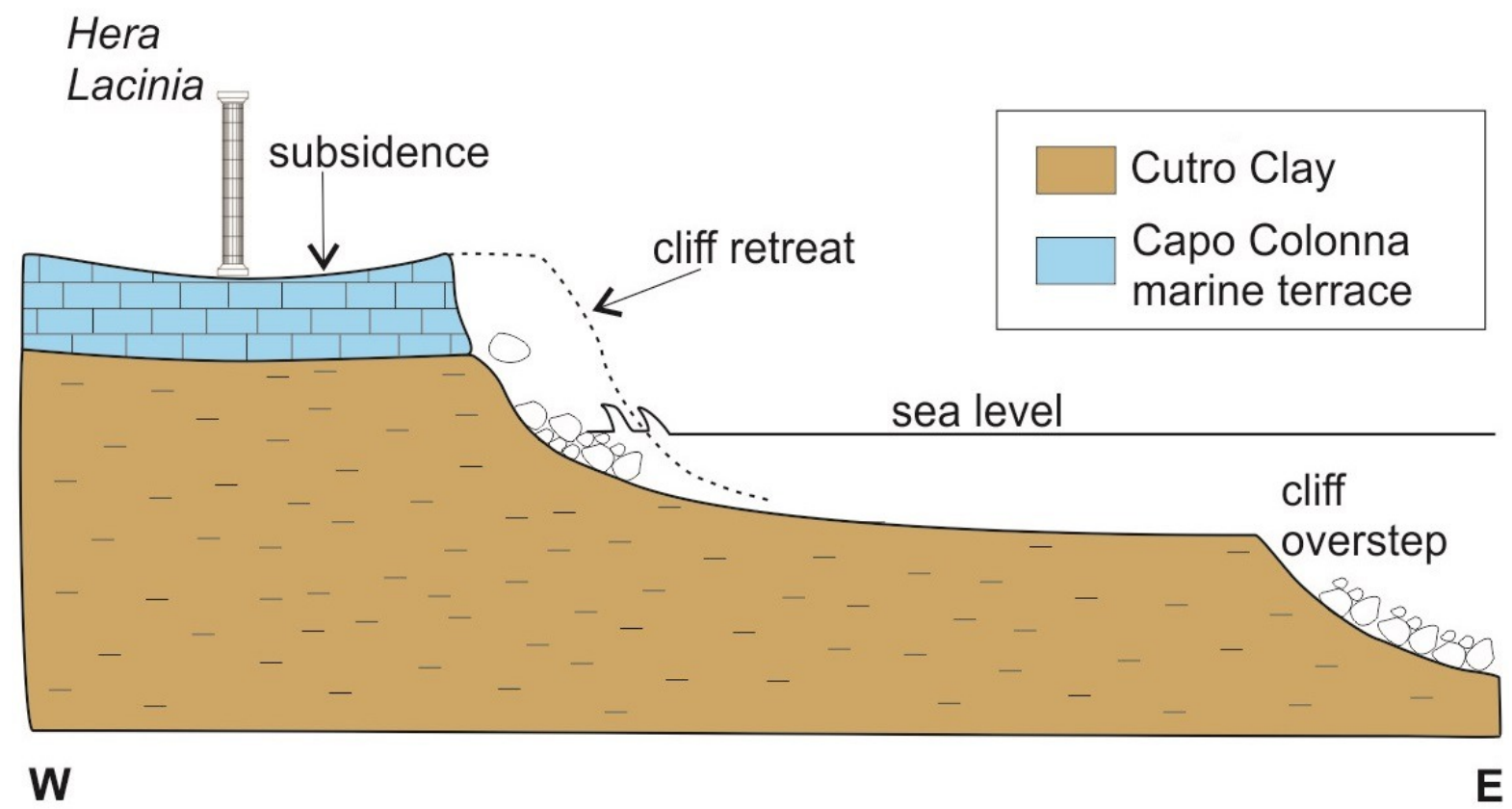

Figure 7. Conceptual model showing the evolution of the Capo Colonna terrace. The coastal cliff is subject to rapid retreat during relative sea-level rise and wave ravinement. Clastic deposits characterise the sedimentation in proximal settings but wave action has not enough time to completely dismantle the cliff. Oversteps are generated and another coastal cliff eventually starts to develop upslope when new conditions of slow relative sea-level rise are established.

It is these inland-sea interactions that the conservation of the archaeological park depends on. With no doubts, the susceptibility to these geohazards has its roots in the local geology. The clays at the base of the cliffs influence the overall stability of the system, as they poorly withstand wave and wind erosion and consequently trigger rock falls and toppling of the overlying lithoid portion [12]. In addition, the Pliocene clays are also affected by widespread gully erosion due to the runoff action of the rainwater. Furthermore, as recalled in section 1, there is evidence of the geological subsidence and submergence of Capo Colonna in the stratigraphic and bathymetric records [7].

The evidence from space, on the other side, shows that the subsidence has never stopped and is still impacting on the residential properties and the lighthouse (cracks and fractures are reported and some of the dwellings have been shored up), as well as on the archaeological ruins, even if restoration and consolidation works were undertaken on the structures themselves over the last years. An example is the Column of Temple A. Despite the restoration completed in 2003 which consisted in mechanical cleaning of the stone and removal of cement integrations [32-33], measurement points located within the pixel cell including the column and the foundation showed a trend of persistent subsidence. This suggests that the conservation strategy should be more holistic, accounting not only for the archaeological asset itself, but more importantly for the asset-geological bedrock combined system.

Similar considerations can be made for the archaeological ruins of the Roman domus in sector 3 (Figure 1 and Figure 4). This can be considered the sector of the archaeological park at highest risk of rockfalls due to the instability of the cliffs. The latest COSMO-SkyMed data allow us to reiterate the assessment stated in earlier InSAR studies [16]. Articles recently appeared in the media confirm the concerns for the conservation of this sector [34]. 
Coastal geohazards may have more impact, however, if we account not only for the archaeological heritage already exposed by the excavations, but also for those structures that have not been discovered yet. Figure 8 shows the cliff edge where one of the towers formerly belonging to the Roman city wall was uncovered during archaeological excavations in 2013. Evidence that this area has been affected by both land subsidence and cliff instability is found in the COSMOSkyMed data (Figure 5a,b), although only with the installation of the corner reflectors a full picture of the movements along the cliff edge was retrieved (Figure 5c). Now that the tower is exposed, its location makes obvious the potential threat, but any rockfall occurred prior to the excavation would have caused irreversible loss of this hidden heritage. Change detection based on Google Earth time-lapse 2009-2015 (Figure 8a-c) and field evidence in November 2015 (Figure 4d) suggest that rockfalls and coastal retreat are already happening in the cliff north-east of the ruins. Field surveys carried out in mid-2016 have confirmed that the distance between the pair of corner reflectors closer to the crack and the cliff edge has decreased to only $\sim 1.1 \mathrm{~m}$.

In this perspective, further research should focus on coastal erosion factors, including directions and strength of winds and waves. Recent studies not only provide coastal retreat rates of up to $\sim 1 \mathrm{~m} /$ year for the eastern sector and up to 0.6 $\mathrm{m} /$ year for the southern sector [10-12], but also point out that powerful wind-driven waves are able to undercut the base of the cliffs [7]. Wind-driven waves add onto the action of seasonally very strong nearshore wave energy and coastal currents transporting sand and fine pebbles that, over time, progressively erode the large rock slabs. Consequently, while land subsidence remains a focus, the next step to develop our research further is the continuation of the satellite monitoring campaign, and its integration with the geomorphological evolution of the coastline and inventory of wavestorms to unveil the complexity of the coastal geohazards threatening the archaeological heritage in Capo Colonna.
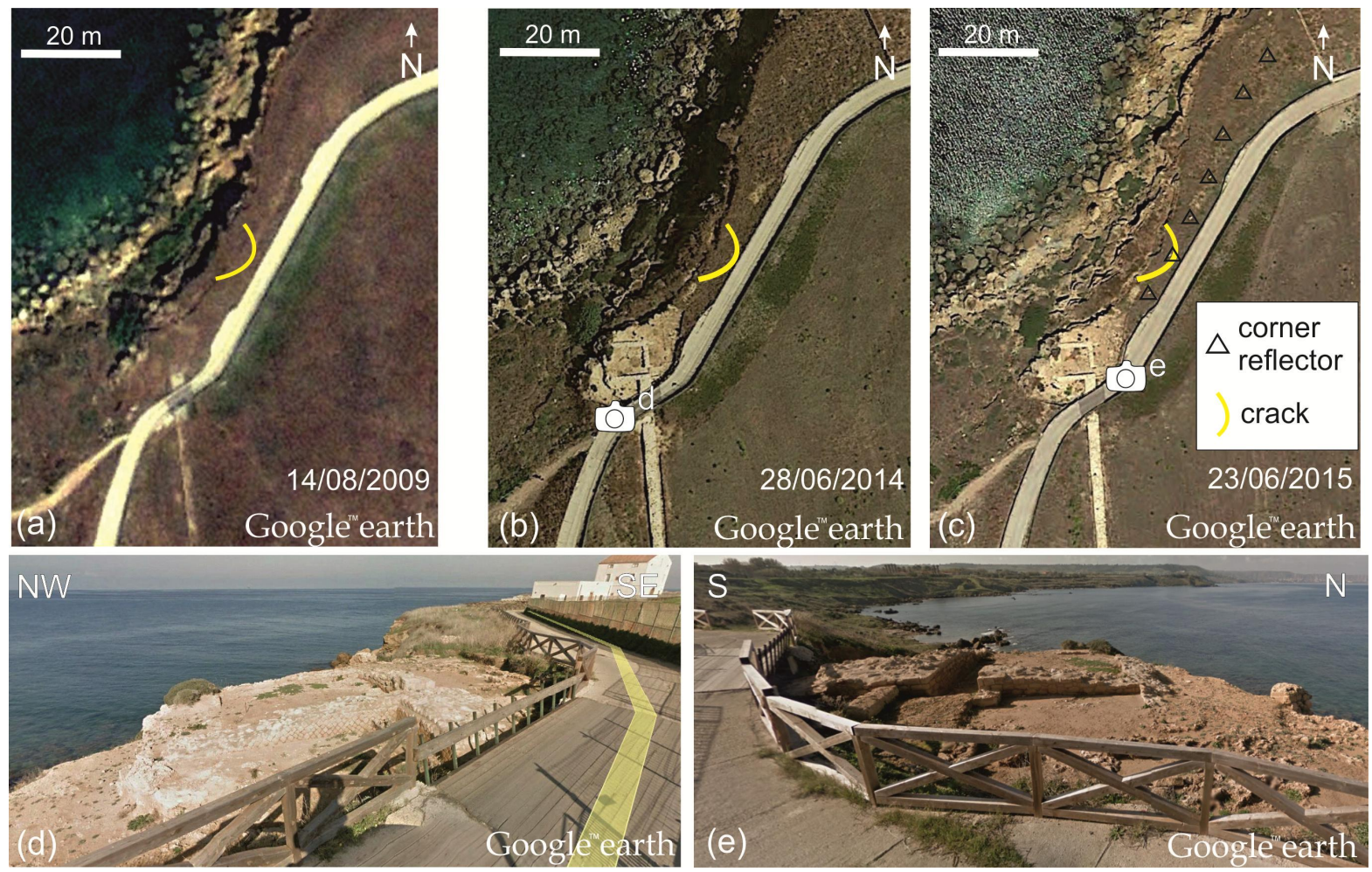

Figure 8. Google Earth time-lapse (a) 14/08/2009, (b) 28/06/2014 and (c) 23/06/2015 of the cliff edge sector west of the balneum and close to the road leading to Nao Tower, where it is apparent the exposure of the ruins of one of the towers of the Roman city walls after the archaeological excavations in 2013. (d-e) Zoomed view of these ruins from the field of view of cameras as captured in Google Earth Street View (Google Earth (C) DigitalGlobe 2016 and Image NASA). The position of $(d-e)$ is shown in (b-c). 


\section{ACKNOWLEDGEMENTS}

ERS-1/2 PSInSAR ${ }^{\mathrm{TM}}$ data and ENVISAT PSP-DIFSAR data from the Extraordinary Plan of Environmental Remote Sensing (EPRS-E) were made available through the National Geoportal of the Italian Ministry of Environment, Territory and Sea (MATTM). COSMO-SkyMed 2011-2014 PSP-DIFSAR data from EPRS-E were made available through a cooperation protocol between MATTM and the Department of Earth, Environment and Resources Sciences, Federico II University of Napoli (departmental funds; coordinator: Prof. D. Calcaterra). TerraSAR-X data were provided by the German Aerospace Centre (DLR) in the framework of the science projects DLR-GEO1589 and GEO2641. COSMOSkyMed 2014-2015 satellite data were acquired by Soprintendenza per $i$ Beni Archeologici della Calabria from the Italian Space Agency (ASI). Sentinel-1A data were made available via the Sentinel-1 Scientific Data Hub of the European Space Agency (ESA). Gas extraction data from well P1 were made available by the Italian Ministry of Economic Development (MISE). The authors thank Soprintendenza per i Beni Archeologici della Calabria, Brigante Engineering and Langella S.r.l. for the installation of the corner reflectors, and Prof. J.J. Mallorquì (Remote Sensing Laboratory of the Universitat Politècnica de Catalunya of Barcelona) for providing the CPT-TSC algorithm. ArcGIS Online basemap: Esri, DigitalGlobe, GeoEye, Earthstar Geographics, CNES/Airbus DS, USDA, USGS, AEX, Getmapping, Aerogrid, IGN, IGP, swisstopo, and the GIS User Community.

\section{REFERENCES}

[1] Bertoni, W., Bratti, C., Carbognin, L., Cesi, C., Chierici, G.L., Dossena, G., Guerricchio, A., La Monica, U., La Tegola, A. and Succetti, A. "Analysis of subsidence in the Crotone area along the Ionian coast of Calabria, Italy," Proc. Sixth International Symposium on Land Subsidence 1, 155-166 (2000).

[2] Bianchini, S. and Moretti, S. "Analysis of recent ground subsidence in the Sibari plain (Italy) by means of satellite SAR interferometry-based methods," International Journal of Remote Sensing 36 (18), 4550-4569 (2015).

[3] Cianflone, G., Tolomei, C., Brunori, C.A. and Dominici, R. "InSAR Time Series Analysis of Natural and Anthropogenic Coastal Plain Subsidence: The Case of Sibari (Southern Italy)," Remote Sensing 7, 16004-16023 (2015).

[4] Vollrath, A., Cianflone, G., Bignami, C., Brunori, C.A., Dominici, R., Zucca, F., Stramondo, S., Baldi, P., Fabris, M., Sepe, V. and Anzidei, M., "Ground deformations along Ionian coastline of the northern Calabria (Southern Italy) from Capo Trionto to Capo Colonna detected by InSAR data," EGU General Assembly Conference Abstracts 17,12585 (2015).

[5] Cucci, L., "Geology versus myth: The Holocene evolution of the Sybaris plain," Ann. Geophys. 48, 1017-1033 (2005).

[6] Ferranti, L., Pagliarulo, R., Antonioli, F., and Randisi, A., "Punishment of the Sinner: Holocene episodic subsidence and steady tectonic motion at ancient Sybaris (Calabria, southern Italy)," Quaternary Int. 232, 56-70 (2011).

[7] Stanley, J.D., Nickerson, G.A., Bernasconi, M.P., Fischer, S., McClure, N., Segal, T. and Royal, J.G., "Multibeam Sonar Technology and Geology to Interpret Ancient Harbor Subsidence off Crotone Peninsula, Italy," Méditerranée 2, 127-141 (2011).

[8] Osanna, M., [Chorai Coloniali da Taranto a Locri: Documentazione archeologica e ricostruzione storica], Istituto Poligrafico e Zecca dello Stato, Libreria dello Stato, 1-247 (1992).

[9] Cerchiai, L., Jannelli, L. and Longo, F., [The Greek Cities of Magna Graecia and Sicily], Getty Publications, Los Angeles, 288 pp. (2004).

[10] Caselli, G., Cocco, E., Gisotti, G. and Spadea, R., "Evoluzione geomorfologica di Capo Colonna (Crotone) nel periodo storico e i suoi rapporti col tempio greco di Hera Lacinia," Boll. Serv. Geol. d'Italia, CXVII, 3-16 (2003).

[11] Lena, G. and Bonomi, S., "Coastal erosion and archaeological monuments in Calabria," Geologia dell'ambiente, 814 (2004).

[12] Ietto,F., Critelli, S. and Federico, M., "Sedimentological and geomorphological features and dynamic of the coastline between Crotone and Le Castella (Ionian Calabria)," Giornale di Geologia Applicata, (10), 13-29 (2008).

[13] Nalin, R. and Massari, F., "Facies and stratigraphic anatomy of a temperate carbonate sequence (Capo Colonna terrace, Late Pleistocene, southern Italy)," Journal of Sedimentary Research, 79(4), 210-225 (2009).

[14] Zecchin, M., Civile, D., Caffau, M. and Roda, C., "Facies and cycle architecture of a Pleistocene marine terrace (Crotone, southern Italy): A sedimentary response to late Quaternary, high-frequency glacio-eustatic changes," Sedimentary Geology, 216(3), 138-157 (2009). 
[15] Chiocchini, U., "Dissesto e rischio sismico dell'area del tempio di Hera Lacinia a Capo Colonna," Proc. of Geoben 2000 - Geological and Geotechnical influences in the Preservation of Historical and Cultural Heritage, edited by G. Lollino (GNDCI - CNR, 2133, Turin) 389-396 (2000).

[16] Tapete, D. and Cigna, F., "Site-specific analysis of deformation patterns on archaeological heritage by satellite radar interferometry," Proc. XX International Materials Research Congress, Symposium 8 Cultural Heritage and Archaeological Issues in Materials Science, MRS Proceedings, 1374, 283-295. Cambridge University Press. doi:10.1557/opl.2012.13972012 (2012).

[17] Del Gaudio, C., Aquino, I., Ricciardi, G.P., Ricco, C. and Scandone, R., "Unrest episodes at Campi Flegrei: A reconstruction of vertical ground movements during 1905-2009," Journal of Volcanology and Geothermal Research, 195(1), 48-56 (2010).

[18] Verdecchia, F., Zoccatelli, C., Norelli, E. and Miandro, R., "Integrated monitoring network for surface deformation in Capo Colonna archaeological area, Crotone, Italy," Hydrological Sci. Journal, 345-351 (2010).

[19] Ministry of the Environment, Territory and Sea - MATTM, "National Geoportal: Extraordinary Plan of Environmental Remote Sensing," http://www.pcn.minambiente.it/GN/progetto pst.php?lan=en (2012).

[20] Ferretti, A., Prati, C. and Rocca, F., "Permanent Scatterers in SAR Interferometry," IEEE Transactions on Geoscience and Remote Sensing 39, 8-20 (2001).

[21] Costantini, M., Iodice, A., Magnapane, L. and Pietranera, L., "Monitoring terrain movements by means of sparse SAR differential interferometric measurements," Proc. Geoscience and Remote Sensing Symposium, 2000. Proceedings. IGARSS 2000. IEEE 2000 International 7, 3225-3227 (2000).

[22] Costantini, M., Minati, F., Ferretti, A., Novali, F., Ciminelli, M.G. and Costabile, S., "SAR interferometry analysis of very large areas: results over the entire Italian territory and discussion of possible worldwide extensions," ESA Living Planet Symposium, Prague, May 2016, paper 2474 (2016).

[23] Berardino, P., Fornaro, G., Lanari, R. and Sansosti, E., "A new algorithm for surface deformation monitoring based on small baseline differential SAR interferograms," IEEE Trans. Geosci. Remote Sensing 40(11), 2375-2383 (2002).

[24] Iglesias, R., Mallorqui, J.J., Monells, D., López-Martínez, C., Fabregas, X., Aguasca, A., Gili, J.A. and Corominas, J., "PSI deformation map retrieval by means of temporal sublook coherence on reduced sets of SAR images," Remote Sensing 7(1), 530-563 (2015).

[25] Sowter, A., Amat, M. B. C., Cigna, F., Marsh, S., Athab, A. and Alshammari, L., "Mexico City land subsidence in 2014-2015 with Sentinel-1 IW TOPS: Results using the Intermittent SBAS (ISBAS) technique," International Journal of Applied Earth Observation and Geoinformation, 52, 230-242 (2016).

[26] Gee, D., Sowter, A., Novellino, A., Marsh, S. and Gluyas, J., "Monitoring land motion due to natural gas extraction: Validation of the intermittent SBAS (ISBAS) DInSAR algorithm over gas fields of North Holland, the Netherlands," Marine and Petroleum Geology, doi: 10.1016/j.marpetgeo.2016.08.014 (2016).

[27] European Space Agency - ESA, "Sentinels Scientific Data Hub,” https://scihub.copernicus.eu (2016).

[28] Confuorto, P., Plank, S., Novellino, A., Tessitore, S. and Ramondini, M., "Implementation of DInSAR methods for the monitoring of heritage sites: Hera Lacinia in Crotone (Southern Italy)," Rendiconti Online - Società Geologica, 4 pp. (Accepted) (2016).

[29] Confuorto P. [From site-scale to large areas monitoring of ground deformation phenomena by integration of different DInSAR techniques in Crotone Province (Southern Italy)], PhD Thesis, Dottorato di Ricerca in Analisi dei Sistemi Ambientali, Università di Napoli Federico II, Anno Accademico 2015/2016, XXVIII Ciclo, 232 pp. (2016).

[30] Hu, J., Li, Z.W., Ding, X.L., Zhu, J.J., Zhang, L. and Sun, Q., "Resolving three-dimensional surface displacements from InSAR measurements: A review," Earth-Science Reviews, 133, 1-17 (2014).

[31] Italian Ministry of Economic Development - MISE, "Profili finali di pozzo, Scheda del pozzo: HERA LACINIA 001," http://unmig.mise.gov.it/unmig/pozzi/dettaglio.asp?cod=3118 (2016).

[32] Spadea R., [Ricerche nel Santuario di Hera Lacinia a Capo Colonna di Crotone. Risultati e prospettive] Roma, (2006).

[33] Palestini C., "La colonna di Hera Lacinia nel Parco archeologico di Capo Colonna a Crotone. Dal rilevamento integrato alla documentazione degli interventi," Progetto, Rappresentazione, Rilievo. Gangemi Editore, pp. 169-183 (2011).

[34] Crotone24news.it, "Capo Colonna, le associazioni lanciano l'allarme: crollo imminente," 18 April 2016, http://www.crotone24news.it/territorio/10607-capo-colonna-le-associazioni-lanciano-l-allarme-crolloimminente.html (2016). 